\title{
Numerical modeling of groundwater flow based on explicit and fully implicit schemes of finite volume method
}

\author{
Hüseyin Y. DALKILIÇ* and Amin GHAREHBAGHI** \\ * Erzincan Binali Ylldırım University, Faculty of Engineering and Architecture, Department of Civil Engineering, Yalnizbag Campus, Erzincan \\ ** Hasan Kalyoncu University, Faculty of engineering, Department of Civil Engineering, Sahinbey, Gaziantep, Turkey \\ *Corresponding Author : hydalkilic@erzincan.edu.tr
}

Submitted :03/12/2019

Revised : $25 / 11 / 2020$

Accepted :05/12/2020

\begin{abstract}
This paper documents a novel numerical model for calculating the behavior of unsteady, one-dimensional groundwater flow by using the finite volume method. The developed model determined water table fluctuations for different scenarios as follows: Drainage and recession from an unconfined aquifer, and water table fluctuations above an inclined leaky layer due to ditch recharge with a constant and variable upper boundary condition. The Boussinesq equation, which is the governing equation in this domain, is linearized and solved numerically in both of the explicit and fully implicit conditions. Meanwhile, the upwind scheme is employed to discretize the governing equation. The computed outcomes of both the explicit and implicit approaches agreed well with the results of analytical solution and laboratory experiments. The main reason is that in the first half of simulation process explicit scheme obtains slightly better results and in the second half of the simulation process fully implicit scheme predicts more reliable outcomes that are hidden in the neighbor node points. As a final point, the numerical outcomes confirm that the developed model is capable of calculating satisfactory outcomes in engineering and science applications.
\end{abstract}

Keywords: Boussinesq Equation, Explicit; Finite Volume Method; Fully Implicit; Groundwater.

\section{INTRODUCTION}

Groundwater is among the tremendously crucial natural resources, which in direct and indirect ways has its own influence to the human life. For instance, the movement of groundwater can spread the contamination, and this process can lead to the environmental disaster. Moreover, simulation of the groundwater flow is important to understand the processes of variations in recharge and drainage of groundwater, fluctuations of groundwater table from a divide to a nearby surface water body, and also manage the recharging of groundwater in semiarid areas. Accordingly, predicting the movement of water through porous media is important for human. Due to the importance of this issue, numerous field and laboratory experiments have been implemented and various analytical and numerical solutions have been established to investigate this hydrological event. As it is known to all, a laboratory or field investigation requires sensitive instruments and large investment in time and money. On the other hand, mostly analytical solutions have limited applications (Gharehbaghi, 2016). Fortunately, one of the effective and powerful 
ways to investigate in this field is numerical method. With dramatic developments that have occurred during recent decades in the field of computer science and mathematics, novel numerical techniques have been developed (Gharehbaghi et al. 2017, Saadatnejadgharahassanlou et al. 2020). The finite volume method (FVM) is one of the most widely used numerical techniques in engineering and science. Thus, in the present paper this method is employed to solve the governing equation. It is worthwhile to mention that, usually, researchers prefer to handle the groundwater flow problems in an unconfined aquifer in the linearized form of the Boussinesq equation. More details about the linearized forms are presented in the following sections of this paper.

The summaries of several studies related to this work are presented as follows. Marino (1973), derived several analytical solutions to determine water table fluctuation in semi-pervious stream-unconfined aquifer systems. One of the assumptions of these analytical expressions was that the storage capacity of the stream bed is negligible. Koussis et al. (1988), investigated groundwater flow over an inclined leaky barrier, and employed the Muskingum-Cunge scheme to predict the "subsurface storm flow" event, which is a kind of runoff that have been caused by rainfall of a near-ground soil zone. Kim \&Ann (2001), employed an acrylic sandbox to analyze the water table in a horizontal unconfined aquifer receiving a uniform recharge and under falling head conditions. Pauwels et al. (2002), provided an analytical solution to the linearized Boussinesq equation for a sloping aquifer and variable recharge inputs with Laplace transforms. Hung et al. (2006), studied the variation of the water table above an inclined leaky barrier when both sides of the boundary level are moving with an exponential form. Rotzoll et al. (2007), introduced a onedimensional (1D) analytical expression for the head distribution in a finite-length, asynchronous dual-tide aquifer, to estimate hydraulic parameters for an unconfined volcanic island aquifer. Yeh et al. (2010), developed an analytical solution for predicting two-dimensional groundwater variations in an unconfined aquifer. They were considered the mean sea level and a first-order free surface equation as initial and upper boundary conditions, respectively. Liang \& Zhang, (2011), suggested an analytical expression for describing the 1D transient groundwater flow from a divide to a river in an unconfined aquifer. They derived the analytical solution for the water table recession and drainage change process described by a linearized Boussinesq equation with a physically based initial condition. Chung et al. (2012), employed a 1D nonlinear governing equation to develop an analytical expression using perturbation analyzes for a coastal leaky aquifer system, comprising an upper unconfined aquifer, a lower semi-confined aquifer, and an aquitard between them. Karan et al. (2013), conducted a field study to understand the effects of spatial heterogeneity on groundwater-stream exchange in a wetland system. In their research, they combined electrical resistivity tomography on land and in a stream with zone-based hydraulic conductivities (from multi-level slug testing). Furthermore, they used a steady-state MODFLOW model to present a numerical model of the problem. Jin et al. (2014), proposed a numerical solution by employing the arbitrary Lagrangian-Eulerian method to solve groundwater flow problem in an unconfined aquifer, formulated as a free-surface problem. It is worthwhile to mention that in the above-mentioned article, problems only solved in a steady state condition. Olsen et al. (2019), announced quadratic and cubic approximate solutions for an unconfined 1D Forchheimer groundwater flow equation for the horizontal propagation of water. Moreover, they constructed a new implementation of Shampine's method for this type of groundwater flow equation. Hayek (2019), provided approximate solutions of the 1D Boussinesq groundwater flow equation in horizontal unconfined aquifers induced by sudden change in boundary head by introducing an analytical technique.

According to the literature review, some researchers have been interested to develop analytical solutions for the groundwater problems. But, as mentioned earlier, these kind of solutions have their own restrictions. This paper aims to develop an effective numerical model for solving the 1D time-dependent Boussinesq equation for predicting the behavior of groundwater flow. Additionally, the other significance and novel point of this paper is that in spite of other researchers who generally have dealt with the subject, just in explicit scheme, in this research both of the explicit and fully implicit schemes are provided. This equation is solved with three groundwater problems. In the first numerical experiment, an analytical solution introduced by Liang \& Zhang (2011), for 1D transient groundwater flow from a divide to a river in an unconfined aquifer is solved. In the last two case studies, laboratory experiments, which 
were conducted by Hung et al. (2006), are selected to predict the water table fluctuations above an inclined leaky layer due to ditch recharge with constant and variable upper boundary conditions.

\section{GOVERNING EQUATION}

Olsen et al. (2019), used the extended form of the Boussinesq equation, which is a nonlinear and nonhomogeneous partial differential equation, to describe the 1D unsteady groundwater flow. This equation is given as follows:

$$
\frac{\partial}{\partial x}\left(h \frac{\partial h}{\partial x}\right)-\tan \theta \frac{\partial h}{\partial x}=\frac{S}{k \cos ^{2} \theta} \frac{\partial h}{\partial t}-\frac{R}{k \cos ^{2} \theta}
$$

where $h, R, \theta, k$, and $S$ are the height of the water table (related to the distance and time), the rate of surface recharge, the angle of the sloping bed with respect to horizontal, the hydraulic conductivity, and the specific yield of the aquifer, respectively.

\section{NUMERICAL AND LABORATORY EXPERIMENTS}

In order to assess the accuracy and the efficiency of the developed model, an analytical solution and two laboratory experiments, which are presented in the literature, are employed. It is crucial to note that the computational process is accomplished with the assist of MATLAB software.

\section{Drainage and Recession From an Unconfined Aquifer}

One of the general hydrologic phenomena in nature is the process of flow from a divide to a free surface water, e.g., rivers, in an unconfined aquifer. Liang \& Zhang (2011), studied this subject and suggested a general analytical solution for drainage and recession from an unconfined aquifer. In this study, they used a hypothetical case to examine the suggested analytical solution. We employed this hypothetical case to validate the results of the proposed model. In this hypothetical case, they assumed the values of the distance, computational time, hydraulic conductivity, recharge rate, the initial height of the water table, the angle of the sloping bed with the horizontal, and surface recharge, as $100 \mathrm{~m}, 10$ days, $2 \mathrm{~m} / \mathrm{d}, 0.01 \mathrm{~m} / \mathrm{d}, 10 \mathrm{~m}, 0$, and 0 , respectively. The illustration of this test case is demonstrated in Fig (1). Because the suggested analytical expression by Liang \& Zhang (2011) was in general form, they did not emphasize on soil types. Therefore, we decided to select the value of specific yield $(S)$ as 0.2 . By substituting the assumptions of the angle of the sloping bed with the horizontal, and surface recharge, the following equation can be obtained.

$\frac{\partial}{\partial x}\left(h \frac{\partial h}{\partial x}\right)=\frac{s}{k} \frac{\partial h}{\partial t}$

The common way to overcome the nonlinearity of the Boussinesq equation is to put it in a linear format. "There are a few ways to linearize the Boussinesq equation" (Liang \& Zhang 2011; Bear 1972). In this paper, the approximation of $h \approx \bar{h}$ is used to linearize Eq. (2).

$\beta \frac{\partial^{2} h^{2}}{\partial x^{2}}=\frac{\partial h^{2}}{\partial t}$ 
where $\beta$ is equal to $k \bar{h} / S$ in which $\bar{h}$ is the average thickness of the aquifer or the average water table above the aquifer bottom. In this case study, the constant head boundary at the river is applied to determine the value of $\bar{h}$ (i.e. $\left.\bar{h}=h_{0}\right)$.

The dimensionless form of analytical expression suggested by Liang \& Zhang (2011), is given as follows:

$$
h^{\prime}=\sqrt{1+\propto \cos \left(\frac{\pi}{2} x^{\prime}\right) \exp \left(-\frac{\pi^{2}}{4} t^{\prime}\right)} h^{\prime}=\frac{h}{h_{0}} \quad x^{\prime}=\frac{x}{L} \quad t^{\prime}=\frac{\beta}{L^{2}} t
$$

Where $\propto$ is equal to $32 R_{r} L^{2} /\left(k h_{0}^{2} \pi^{3}\right)$ in which $R_{r}$ is a constant recharge rate. By some replacement, the following expression can be derived.

$$
\frac{h}{h_{0}}=\sqrt{1+\propto \cos \left(\frac{\pi}{2} \frac{x}{L}\right) \exp \left(-\frac{\pi^{2}}{4} \frac{\beta}{L^{2}} t\right)}
$$

Meanwhile, the initial and boundary conditions are employed as follows:

$$
h(x, 0)=f(x) \quad h(0, t)=0 \quad h(L, t)=h_{0}
$$

where $f(x)=h_{0} \sqrt{1+\propto \cos \left(\frac{\pi x}{2 L}\right)}$.

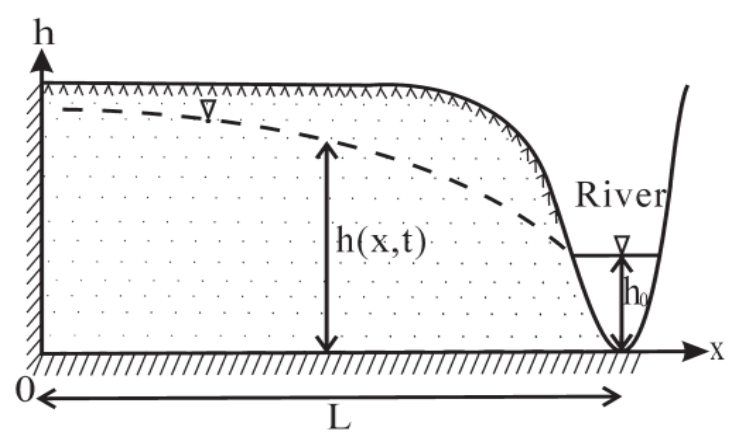

Figure 1: Illustration of the groundwater flow from a divide to a free surface water (Liang \& Zhang 2011)

\section{Water Table Fluctuations Above an İnclined Leaky Layer due to Ditch Recharge with a Variable Upper Boundary Condition}

One of the effective methods for raising a water table is ditch recharge. But, leaky layer shows its own influence on the efficiency of the recharge when an aquifer is lying on it. Hung et al. (2006), by using a sandbox model, studied this problem. In this research, they used the following assumptions: "1) The pressure of the lower aquifer is zero; 2) the upper and lower portions of the aquifers are homogeneous and isotropic, as is the leaky bed layer; 3) The hydraulic conductivity of the leaky layer is much smaller than that of the upper and lower aquifers; 4) The effects due to capillary rise and evaporation from the water table are ignored; 5) The flow is characterized by a one-dimensional 
continuity equation, as derived by Boussinesq in 1904 using Darcy's law and Dupuit's assumption“(Hung et al., 2006).

By considering the rate of surface recharge equal to zero, a leaky bed, and linearized form of Eq. (1) similar to the previous case, the following form of Eq. (1) can be extracted.

$\frac{\partial^{2} h^{2}}{\partial x^{2}}-\frac{\tan \theta}{\bar{h}} \frac{\partial h^{2}}{\partial x}=\frac{S}{\bar{h} k \cos ^{2} \theta} \frac{\partial h^{2}}{\partial t}+\frac{2 k^{*}}{\bar{h} b k \cos ^{2} \theta} h^{2}+\frac{2 k^{*}}{k \cos ^{2} \theta}$

Where $k^{*}$ and $b$ are the vertical hydraulic conductivity and the vertical thickness of the leaky bed, respectively. In order to present a simpler form of Eq. (7), the following equation and parameters are introduced.

$\frac{\partial^{2} h^{2}}{\partial x^{2}}-B \frac{\partial h^{2}}{\partial x}=C \frac{\partial h^{2}}{\partial t}+D h^{2}+Q$

Where $B=\frac{\tan \theta}{\bar{h}}, C=\frac{S}{\bar{h} k \cos ^{2} \theta}, D=\frac{2 k^{*}}{\bar{h} b k \cos ^{2} \theta}$, and $Q=\frac{2 k^{*}}{k \cos ^{2} \theta}$.

As an earlier case, the value of $\bar{h}$ is used to linearize the Boussinesq equation. Nevertheless, not similar to the first numerical experiment, in this and the next case in order to obtain accurate approach, the value of $\bar{h}$ calculated as $\bar{h}=0.5\left(h_{0}(t)+h_{L}(t)\right)$. In the present case study, the initial and boundary conditions are written as follows:

$h(x, 0)=h_{i c}(x) \quad h(0, t)=h_{0}(t) \quad h(L, t)=h_{L}(t)$

where $h_{i c}(x)$ is the initial height of the water table. More details about initial and boundary conditions are given in Figs. (2 and 6). Brief details of the experimental setup, studied by Hung et al. (2006), which is used in this and the next numerical experiment, are presented here.

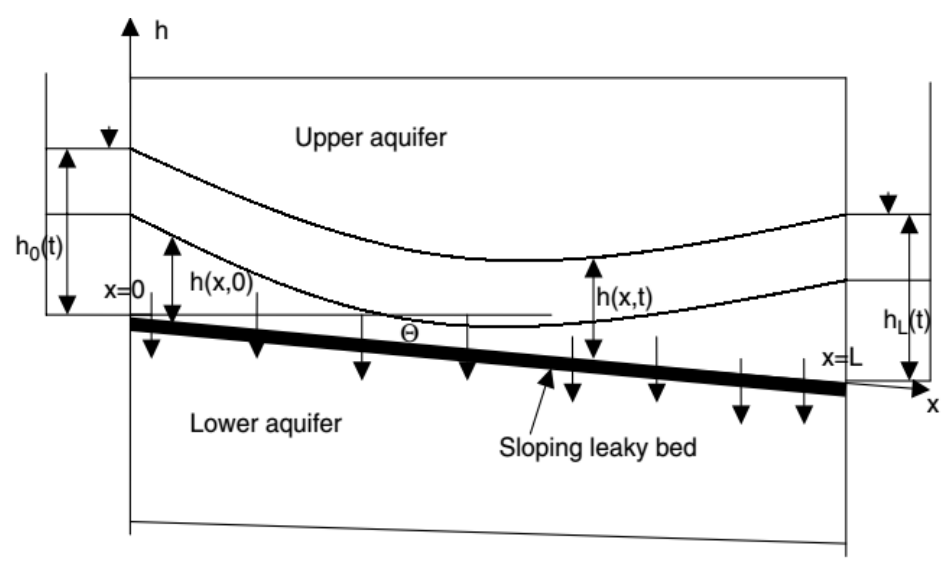

Figure 2. Illustration of water table (Hung et al., 2006) 
Laboratory experiments were carried out on a sandbox model with $15 \mathrm{~cm}$ wide $\times 70 \mathrm{~cm}$ high $\times 240 \mathrm{~cm}$ long. The above mentioned model was made of acrylic plates, and these plates were $5 \mathrm{~cm}$ thick. The side walls of the sandbox were contained two rows of 13 holes with $1 \mathrm{~cm}$ diameter. Totally, two reservoirs were designed at the ends of each side of the sandbox. The aquifers were formed by two sand materials. The illustration of this sandbox model is given in Fig. (3). The sandbox model and hydraulic parameters were measured as below.

The value of distance was $240 \mathrm{~cm}$, the computation time was $8 \mathrm{~min}$, hydraulic conductivity was $0.2 \mathrm{~cm} / \mathrm{s}$, specific yield was 0.18 , vertical hydraulic conductivity was $0.00025 \mathrm{~cm} / \mathrm{s}$, the slope angle was $3 \%$ and the vertical thickness of the leaky bed was $5 \mathrm{~cm}$.

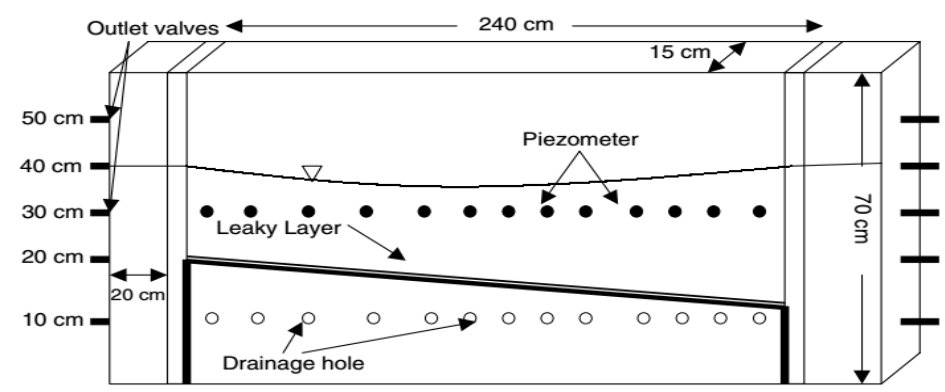

Figure 4. Illustration of the sandbox model (Hung et al., 2006)

\section{Water Table Fluctuations Above an Inclined Leaky Layer Due to Ditch Recharge with a Constant Upper Boundary Condition}

This laboratory experiment is similar to the second case study. The main difference is in the boundary conditions. In this case, the upper boundary condition is selected as a constant value.

$h(x, 0)=h_{i c}(x) h(0, t)=h_{0} \quad h(L, t)=h_{L}(t)$

where the value of $\mathrm{h} 0$ is $17.8 \mathrm{~cm}$. More details about the initial and boundary conditions are illustrated in Figs. (2 and 7).

\section{NUMERICAL MODELING}

As highlighted earlier, in this paper, the explicit and fully implicit schemes of FVM are employed for three groundwater problems. The 1D discretization of FVM is demonstrated in Fig.(4).

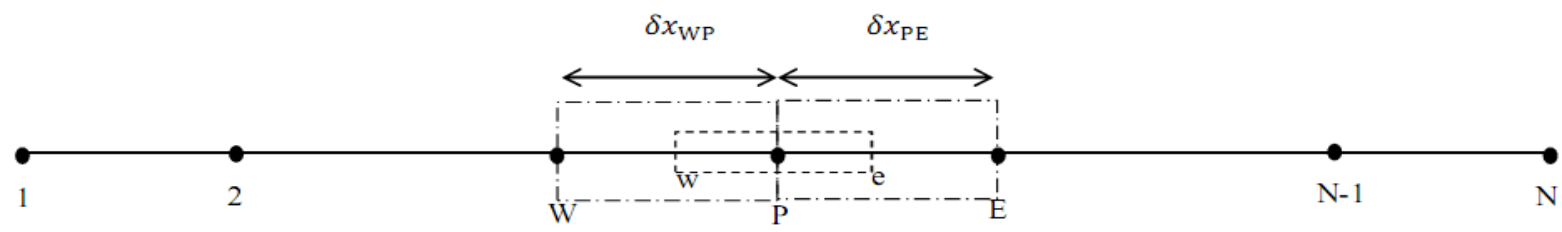

Figure 4. 1D discretization of FVM (Gharehbaghi 2017) 
"In this figure, $P, E, W, e$, and $w$ are the target nodal point that must be calculated, the eastern neighbor node, the western neighbor node, the east side face of the control volume, and the west side face of the control volume, respectively. Furthermore, $\delta x$ with different subscripts shows distances between the nodes." (Gharehbaghi 2017).

\section{Numerical Modeling of Drainage and Recession From an Unconfined Aquifer}

As underlined previously, in the first case study, the Boussinesq equation expressed in Eq. (3), and the initial and boundary conditions given in Eq. (6), are used. The integral form of Eq. (3) can be written as follows:

$\int_{t}^{t+\Delta t} \int_{C V} \frac{\partial h^{2}}{\partial t} d V d t=\int_{t}^{t+\Delta t} \int_{C V} \beta \frac{\partial^{2} h^{2}}{\partial x^{2}} d V d t$

Integration of the Eq. (11) over a time interval from $t$ to $t+\Delta t$ and over the control volume is given as follows:

$\left(h^{2}{ }_{p}-h_{p}^{20}\right) \Delta V=\beta\left[\left(A_{e} \frac{h^{2} E^{-} h^{2} P}{\Delta x_{P E}}\right)-\left(A_{w} \frac{h^{2}{ }^{2}-h^{2} w}{\Delta x_{P W}}\right)\right] \Delta t$

In Eq. (12), $\Delta V$ is the volume of the control volume, which is equal to the face area of the control volume $\left(A_{e}=A_{w}=A\right.$ ) multiplied by the width of the control volume ( $\partial x$ ). By dividing both sides of Eq. (12) to $A$ and with some manipulations, the general explicit and fully implicit solutions of the Boussinesq equation with FVM is written as follows:

$h^{2}{ }_{p}=\vartheta \frac{\Delta t}{\Delta x}\left[\beta\left[\left(\frac{h^{2} E^{-} h^{2} P}{\Delta x_{P E}}\right)-\left(\frac{h^{2} P-h^{2} W}{\Delta x_{P W}}\right)\right]\right]+(1-\vartheta) \frac{\Delta t}{\Delta x}\left[\beta\left[\left(\frac{h^{2} E^{-} h^{2} P}{\Delta x_{P E}}\right)-\left(\frac{h^{2} P^{-} h^{2} W}{\Delta x_{P W}}\right)\right]^{0}\right]+h^{2^{0}}$

It is worthwhile to mention that in terms of Eq. (13) superscript " 0 " is the values at time $t$ (old time). But the values at time level $t+\Delta t$ (new time) are without superscripted. By replacing the value of $\vartheta$ as zero and one for explicit and fully implicit schemes, respectively, and with some manipulations, the explicit and fully implicit schemes of solutions are obtained as follows:

Explicit solution

$h_{p}=\sqrt{\beta \frac{\Delta t}{\Delta x^{2}}\left[h_{E}^{2}{ }^{0}-2 h_{P}^{2}{ }^{0}+h^{2}{ }^{0}{ }^{0}\right]+h^{20}{ }_{p}}$

Fully Implicit solution

$$
\left(1+2 \beta \frac{\Delta t}{\Delta x^{2}}\right) h_{P}^{2}-\beta \frac{\Delta t}{\Delta x^{2}} h_{E}^{2}-\beta \frac{\Delta t}{\Delta x^{2}} h^{2}{ }_{W}={h^{2}}_{p}^{0}
$$

The fully implicit solution is required to solve in a matrix form. Thus, the matrix form of the Eq. (15) is rearranged as follows: 


$$
\begin{aligned}
& S=\left[\begin{array}{ccccccc}
1+2 \beta \frac{\Delta t}{\Delta x^{2}} & -\beta \frac{\Delta t}{\Delta x^{2}} & 0 & 0 & \ldots & \ldots & 0 \\
-\beta \frac{\Delta t}{\Delta x^{2}} & \left(1+2 \beta \frac{\Delta t}{\Delta x^{2}}\right) & -\beta \frac{\Delta t}{\Delta x^{2}} & 0 & \ldots & 0 & 0 \\
0 & -\beta \frac{\Delta t}{\Delta x^{2}} & \left(1+2 \beta \frac{\Delta t}{\Delta x^{2}}\right) & -\beta \frac{\Delta t}{\Delta x^{2}} & 0 & \ldots & 0 \\
0 & 0 & \ddots & \ddots & \ddots & \ddots & 0 \\
0 & 0 & 0 & \cdots & -\beta \frac{\Delta t}{\Delta x^{2}} & 1+2 \beta \frac{\Delta t}{\Delta x^{2}} & -\beta \frac{\Delta t}{\Delta x^{2}} \\
0 & 0 & 0 & \cdots & 0 & 1+2 \beta \frac{\Delta t}{\Delta x^{2}} & -\beta \frac{\Delta t}{\Delta x^{2}}
\end{array}\right]
\end{aligned}
$$

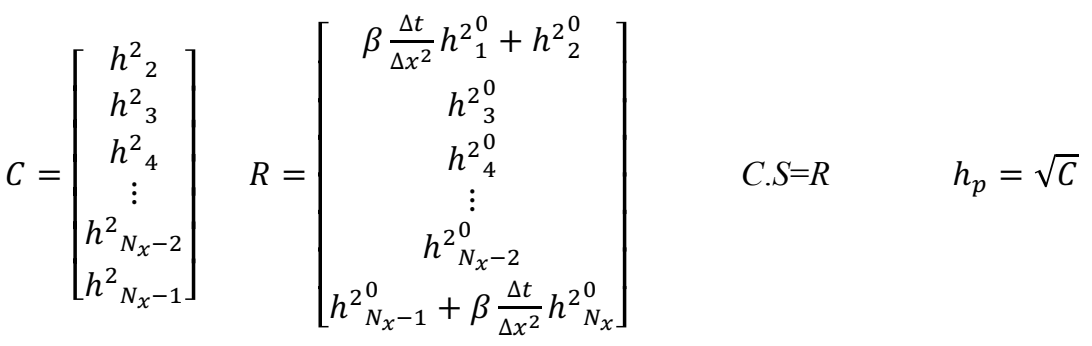

\section{Numerical Modeling of Water Table Fluctuations Above an Inclined Leaky Layer Due to Ditch Recharge With a Variable Upper Boundary Condition}

In the second test case, the initial and boundary conditions, which are presented in Eq. (9), are used. Therefore, the integral form of Eq. (8) is expressed as follows:

$$
\int_{t}^{t+\Delta t} \int_{C V} \frac{\partial h^{2}}{\partial t} d V d t=\int_{t}^{t+\Delta t} \int_{C V} \frac{1}{C} \frac{\partial^{2} h^{2}}{\partial x^{2}} d V d t-\int_{t}^{t+\Delta t} \int_{C V} \frac{B}{C} \frac{\partial h^{2}}{\partial x} d V d t-\int_{t}^{t+\Delta t} \int_{C V} \frac{D}{C} h^{2}-\int_{t}^{t+\Delta t} \int_{C V} \frac{Q}{C}
$$

Like the pervious case study, integration of the Eq. (10) over a time interval from $t$ to $t+\Delta t$ and over the control volume can be written as follows:

$$
\left(h_{p}^{2}-h_{p}^{20}\right) \Delta V=\frac{1}{C}\left[\left(A \frac{\partial h^{2}}{\partial x}\right)_{e}-\left(A \frac{\partial h^{2}}{\partial x}\right)_{w}\right] \Delta t-\frac{B}{C}\left[\left(A h^{2}\right)_{e}-\left(A h^{2}\right)_{w}\right] \Delta t-\frac{D}{C} h^{2} \Delta V \Delta t-\frac{Q}{C} \Delta V \Delta t
$$

To achieve the appropriate form of the discretized equation, the values of interface coefficients $h_{e}^{2}$ and $h^{2}{ }_{w}$, and the gradient $\partial h^{2} / \partial x$ at the east and west sides, are strongly important. Consequently, scientists developed numerous approaches for this purpose. In this paper, for the second and third numerical experiments, the first order upwind approach is used as follows:

Upwind scheme

$h_{e}=h_{P}, \quad h_{w}=h_{W}$

$\left(h^{2}{ }_{p}-h_{p}^{20}\right) \Delta V=\frac{1}{C}\left[\left(A_{e} \frac{h^{2} E^{-} h^{2} P}{\Delta x_{P E}}\right)-\left(A_{w} \frac{h^{2}{ }_{P}-h^{2} W}{\Delta x_{P W}}\right)\right] \Delta t-\frac{B}{C}\left[A h^{2}{ }_{P}-A h^{2}{ }_{W}\right] \Delta t-\frac{D}{C} h^{2} \Delta V \Delta t-\frac{Q}{C} \Delta V \Delta t$ 
As same as earlier test case, with regard to the equality of $(\mathrm{Ae}=\mathrm{Aw}=\mathrm{A})$ and with some simplifications, the following expression is extracted.

$$
\begin{aligned}
& h^{2}{ }_{p}=\vartheta \frac{\Delta t}{\Delta x}\left[\frac{1}{C}\left[\left(\frac{h^{2} E^{-} h^{2} P}{\Delta x_{P E}}\right)-\left(\frac{h^{2}{ }_{P}-h^{2} W}{\Delta x_{P W}}\right)\right]-\frac{B}{C}\left[h^{2}{ }_{P}-h^{2}{ }_{W}\right]-\frac{D}{C} h^{2} \Delta x\right]+(1-\vartheta) \frac{\Delta t}{\Delta x}\left[\frac{1}{C}\left[\left(\frac{h^{2} E^{-} h^{2} P}{\Delta x_{P E}}\right)-\left(\frac{h^{2}{ }_{P}-h^{2} W}{\Delta x_{P W}}\right)\right]-\right. \\
& \left.\frac{B}{C}\left[h^{2}{ }_{P}-h^{2}{ }_{W}\right]-\frac{D}{C} h^{2} \Delta x\right]^{0}+h^{2}{ }_{p}^{0}-\frac{Q}{C} \Delta x
\end{aligned}
$$

where in terms of Eq. (21) superscript " $O$ " refers to the value at time $t$ (old time). After all, with some manipulations and substitutions, the final explicit and fully implicit forms of solutions are obtained as follows;

Explicit solution;

$h_{p}=\sqrt{\frac{\Delta t}{C}\left[\frac{1}{\Delta x^{2}}\left(h^{2}{ }_{E}^{0}-2 h^{2}{ }_{P}^{0}+h^{2}{ }_{W}^{0}\right)-\frac{B}{\Delta x}\left[h^{2}{ }_{p}^{0}-h^{2^{0}}\right]-D h^{2}{ }_{p}^{0}\right]+h^{2}{ }_{p}^{0}-Q}$

Fully Implicit solution

$h^{2}{ }_{p}\left(1+\frac{\Delta t}{C} \frac{2}{\Delta x^{2}}+\frac{\Delta t}{C} \frac{B}{\Delta x}+\frac{\Delta t}{C} D\right)-\frac{\Delta t}{C} \frac{1}{\Delta x^{2}} h_{E}^{2}-h^{2}{ }_{W}\left(\frac{\Delta t}{C} \frac{1}{\Delta x^{2}}+\frac{\Delta t}{C} \frac{B}{\Delta x}\right)=h_{p}^{20}-\frac{\Delta t}{C} Q$

Similar to the previous case study, the fully implicit scheme of solution is required to solve as a matrix form. Moreover, as it is known in all of the case studies, the explicit solutions must be able to satisfy the stability condition. In this paper, the authors applied Courant number for examining the stability condition.

\section{Numerical Modeling of Water Table Fluctuations Above an Inclined Leaky Layer Due to Ditch Recharge With a Constant Upper Boundary Condition}

This case is similar to the second case. The main difference is in the upper boundary condition. In this numerical experiment, the initial and boundary conditions, which is described in Eq. (10), is employed to solve the Eq. (8). Therefore, the explicit and fully implicit forms of solution are as same as Eqs. (22-23).

\section{RESULTS AND DISCUSSION}

In the present paper, the explicit and fully implicit schemes of FVM are used to discretize the Boussinesq equation. Accordingly, one problem with obvious analytical expression and two laboratory experiments are selected to examine the developed model. The details of these case studies are presented in Table (1). It must be noted that in tables and figures below, the first, second and third case studies are referred to as drainage and recession from an unconfined aquifer, water table fluctuations above an inclined leaky layer due to ditch recharge with a variable upper boundary condition, and water table fluctuations above an inclined leaky layer due to ditch recharge with a constant upper boundary condition, respectively. In all of the case studies, the uniform node distribution is considered to model the problem domain. The results of these case studies are demonstrated in Figs. (5-7) and tables (2) and (3). These figures include the plots of the height of the water table versus distance in several times. 
Meanwhile, in the following figures and tables, the Ex, Obs, Exp, and Imp are the abbreviations of, the results of analytical solution introduced by Liang \& Zhang, (2011), the results of experimental study, the explicit results and the fully implicit results, respectively. The first case is solved with time and distance intervals as $\Delta \mathrm{t}=0.0033$ day $\left(N_{t}=3001\right)$, and $\Delta \mathrm{x}=1 \mathrm{~m}\left(N_{x}=101\right)$, respectively. But in the second and third case studies, the values of time and distance intervals are selected to be $\Delta \mathrm{t}=0.0480 \mathrm{sec}$. $\left(N_{t}=10001\right)$, and $\Delta \mathrm{x}=8.2759 \mathrm{~cm}\left(N_{x}=30\right)$, respectively. As it is seen in Figs. (5-7), the results of explicit and fully implicit schemes are very close to each other. Hence, in order to make a better comparison about numerical outcomes, Eq. (24) is used. Finally, the results of the comparison are given in tables (2) and (3).

dimensionless differences $=\frac{[(\text { Explicit or fully Implicit })-\text { Exact }]^{2}}{N_{x}}$

With regard to the results achieved, it can be concluded that both of the explicit and fully implicit approaches, can determine reliable outcomes and show close agreement with the predictions of analytical solution and laboratory experiments. From Fig. (6) it is evident that with the passage of the time and achieve an advance in experiment, the sections of the model through the charging area in the end of the measurement give the largest deviations. For instance, at the $6^{\text {th }} \mathrm{min}$, the values of water table depth at distance $(\mathrm{x}=35.00318)$, for Obs and Exp are measured as 23.86032 and 24.75415 , respectively, and at the $8^{\text {th }} \mathrm{min}$, the values of water table depth for the same distance (i.e. $\mathrm{x}=$ 35.00318), for Obs and Exp are measured as 25.15534 and 26.3136, respectively. Marino (1967), in his experimental study reported that the larger deviations in this region were possibly due to the observational errors, since in this region the water levels were generally changing rapidly and consequently were difficult to observe accurately. As in the third case study, by selecting the constant value for charging area this problem is eliminated. Based on the values of dimensionless differences given in tables (2) and (3), in the first case study, the results of explicit scheme are slightly better. However, in the second and third case studies, in the first half of the simulation ( $\mathrm{t}=2 \mathrm{sec}$. and $4 \mathrm{sec}$.) the results of explicit scheme are slightly better and in the last half of the simulation process $(\mathrm{t}=6 \mathrm{sec}$. and $8 \mathrm{sec}$.) the results of fully implicit scheme are better. Based upon our observations in numerical experiments, the main cause of this variation is related to the neighbor node points. Nevertheless, it is worthwhile to mention that the amount of variation is exceedingly small and both of the approaches can use to solve the engineering problems and science.

Table 1. Table of parameters

\begin{tabular}{|c|c|c|c|c|c|c|c|c|c|}
\hline & $\boldsymbol{x}$ & $\boldsymbol{t}$ & $\boldsymbol{k}$ & $\boldsymbol{k}^{*}$ & $\boldsymbol{R} \boldsymbol{h}$ & $\boldsymbol{h} \boldsymbol{\text { S(dimensionless) }}$ & $\boldsymbol{\theta}$ & $\boldsymbol{R}$ \\
\hline $\begin{array}{c}\text { First } \\
\text { case }\end{array}$ & $100 \mathrm{~m}$ & $\begin{array}{c}10 \\
\text { days }\end{array}$ & $2 \mathrm{~m} / \mathrm{d}$ & - & $\begin{array}{c}0.01 \\
\mathrm{~m} / \mathrm{d}\end{array}$ & $10 \mathrm{~m}$ & 0.2 & 0 & 0 \\
\hline $\begin{array}{c}\text { Second } \\
\text { case }\end{array}$ & $\begin{array}{c}240 \\
\mathrm{~cm}\end{array}$ & $8 \mathrm{~min}$ & $\begin{array}{c}0.2 \\
\mathrm{~cm} / \mathrm{s}\end{array}$ & $\begin{array}{c}0.000 \\
25 \mathrm{~cm} / \mathrm{s}\end{array}$ & - & $\begin{array}{c}\text { Presented in } \\
\text { Fig. (3) }\end{array}$ & 0.18 & $3 \%$ & 0 \\
\hline $\begin{array}{c}\text { Third } \\
\text { case }\end{array}$ & $\begin{array}{c}240 \\
\mathrm{~cm}\end{array}$ & $8 \mathrm{~min}$ & $\begin{array}{c}0.2 \\
\mathrm{~cm} / \mathrm{s}\end{array}$ & $\begin{array}{c}0.000 \\
25 \mathrm{~cm} / \mathrm{s}\end{array}$ & - & $\begin{array}{c}\text { Presented in } \\
\text { Fig. (4) }\end{array}$ & 0.18 & $3 \%$ & 0 \\
\hline
\end{tabular}




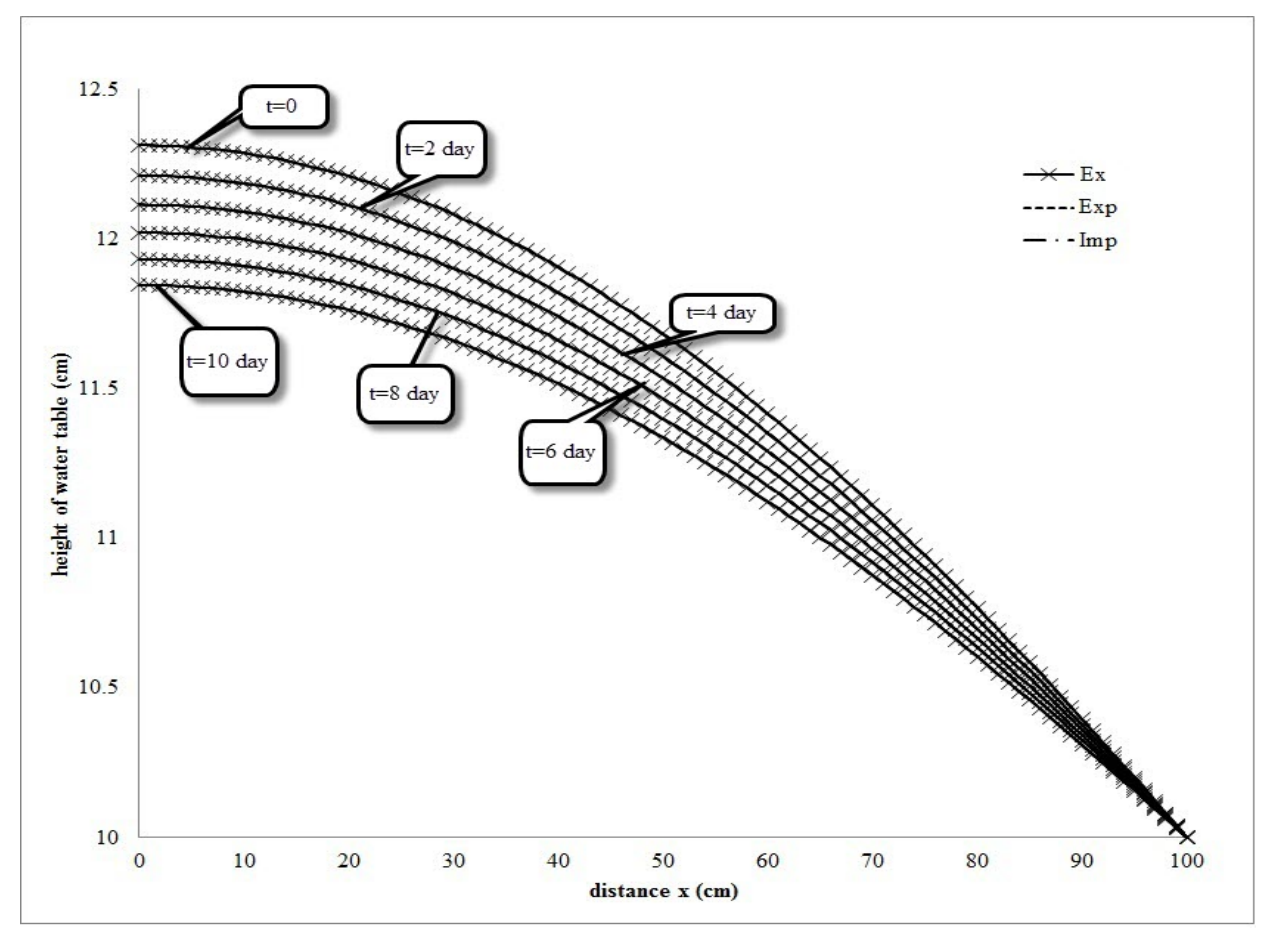

Figure 5. Illustration of results for the first case

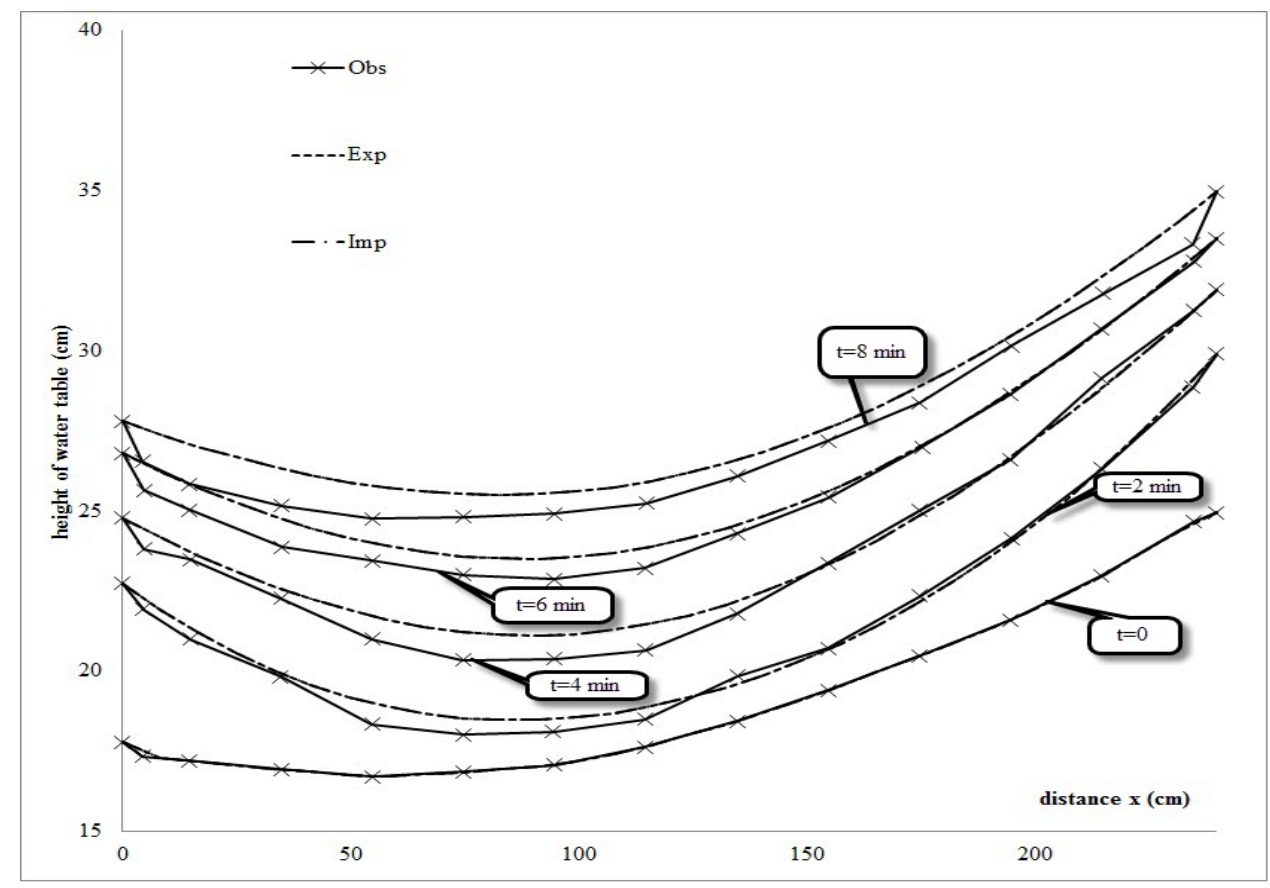

Figure 6. Illustration of results for the second case 


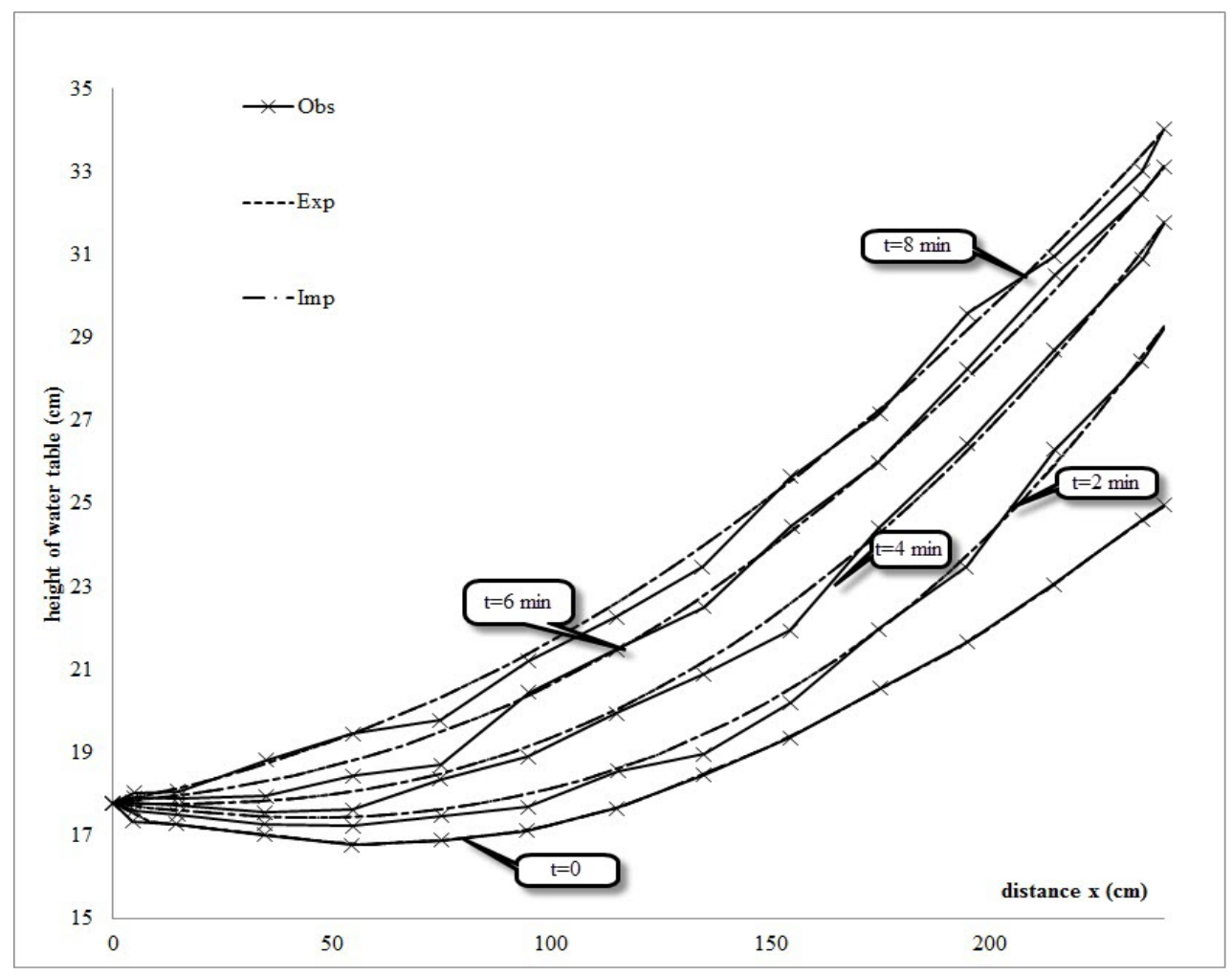

Figure 7. Illustration of results for the third case

Table 2. Table of dimensionless differences in the first case

\begin{tabular}{|l|l|c|l|l|l|c|}
\hline & schemes $\boldsymbol{t}$ & \multicolumn{1}{|c|}{$\mathbf{2 d a y}$} & \multicolumn{1}{|c|}{$\mathbf{4}$ day } & \multicolumn{1}{|c|}{$\mathbf{6}$ day } & $\mathbf{8}$ day & $\mathbf{1 0}$ day \\
\hline \multirow{2}{*}{ First case } & Exp & $1.53912 \mathrm{E}-12$ & $4.73 \mathrm{E}-12$ & $8.37 \mathrm{E}-12$ & $1.18 \mathrm{E}-11$ & $1.48 \mathrm{E}-11$ \\
\cline { 2 - 7 } & $\mathrm{Imp}$ & $1.38419 \mathrm{E}-11$ & $4.25799 \mathrm{E}-11$ & $7.53103 \mathrm{E}-11$ & $1.06 \mathrm{E}-10$ & $1.33 \mathrm{E}-10$ \\
\hline
\end{tabular}

Table 3. Table of dimensionless differences in the second and third cases

\begin{tabular}{|l|l|c|c|c|c|l|}
\hline & schemes $\mid \boldsymbol{t}$ & \multicolumn{1}{|c|}{$\mathbf{m i n}$} & $\mathbf{4 m i n}$ & $\mathbf{6 m i n}$ & $\mathbf{8 m i n}$ & 10min \\
\hline \multirow{2}{*}{ Second case } & Exp & 0.079595204 & 0.210144 & 0.227608 & 0.522923 & - \\
\cline { 2 - 7 } & $\operatorname{Imp}$ & 0.079735193 & 0.210164 & 0.227502 & 0.522504 & - \\
\hline \multirow{2}{*}{ Third case } & $\operatorname{Exp}$ & 0.040487441 & 0.056326 & 0.073762 & 0.061418 & - \\
\cline { 2 - 7 } & $\operatorname{Imp}$ & 0.040511772 & 0.056293 & 0.073755 & 0.061324 & - \\
\hline
\end{tabular}




\section{CONCLUSION}

In the present study, the Boussinesq equation is solved with explicit and fully implicit schemes of FVM. The comprehensive analyze is provided by using three analytical and laboratory experiments as follows: (i) Drainage and recession from an unconfined aquifer, (ii) Water table fluctuations above an inclined leaky layer due to ditch recharge with a variable upper boundary condition, and (iii) Water table fluctuations above an inclined leaky layer due to ditch recharge with a constant upper boundary condition. Both of the approaches used in this research, are presented good agreement with analytical solution and laboratory experiments. To make a more reliable comparison between the approaches, dimensionless differences of the results are calculated. According to the results provided in tables 2 and 3 , in the first half of simulation process explicit scheme obtains slightly better results. For instance, at the $2^{\text {nd }} \mathrm{min}$ of second case, the values of dimensionless differences in explicit form calculated as 0.079595204 and in implicit form the values of dimensionless differences calculated as 0.079735193. Nevertheless, in the second half of the simulation process fully implicit scheme predicts more reliable outcomes. For example, for the same case at the $8^{\text {th }} \mathrm{min}$ the dimensionless difference values in explicit and fully implicit forms calculated as 0.522923 and 0.522504 , respectively. The key reason for this event is hidden in the neighbor node points. In the second case, the main reason of observing a difference between the measured and developed model results is related to the observational errors in measuring of experimental data. For instance, the values of water table depth at the $8^{\text {th }}$ min, at distance $(x=35.00318)$, for Obs and Exp are measured as 25.15534 and 26.3136, respectively. Consequently, by selecting the constant value for charging area and measuring groundwater table more sensitively, this problem is easily eliminated in the third case study. As a final point, the numerical outcomes confirm that the developed model is capable of calculating satisfactory outcomes in engineering and science applications.

\section{ACKNOWLEDGEMENT}

This research did not receive any specific grant from funding agencies in the public, commercial, or not-forprofit sectors.

\section{REFERENCES}

Bear, J. 1972. Dynamics of Fluids in Porous Media. American Elsevier Publishing Company Inc. New York

Chuang, M.H., Mahdi, A.A. \& Yeh, H.D. 2012. A perturbation solution for head fluctuations in a coastal leaky aquifer system considering water table over-height. Hydrological Sciences Journal 57: (1), 162-172, Doi: 10.1080/02626667.2011.637496.

Gharehbaghi, A., Kaya, B. \& Saadatnejadgharahassanlou, H. 2017. Two dimensional bed variation models under non-equilibrium conditions in turbulent streams. Arab J. Sci. Eng. 42: 999-1011, Doi 10.1007/s13369016-2258-4.

Gharehbaghi, A. 2016. Explicit and Implicit Forms of Differential Quadrature Method for Advection-Diffusion Equation with Variable Coefficients in Semi-infinite Domain. Journal of Hydrology 541 : 935-940, Doi.org/10.1016/j.jhydrol.2016.08.002.

Gharehbaghi, A. 2017. Third- and fifth-order finite volume schemes for advection-diffusion equation with variable coefficients in semi-infinite domain. Water and Environment Journal 31: 184-193, doi:10.1111/wej.12233.

Hayek, M. 2019. Accurate approximate semi-analytical solutions to the Boussinesq groundwater flow equation for recharging and discharging of horizontal unconfined aquifers. Journal of Hydrology doi:https://doi.org/10.1016/j.jhydrol.2018.12.057. 
Hung, C.J., Tan, Y.C., Chen, C.H., Chen, J.M. \& Chang, PW. 2006. Analytical solution of water table fluctuations above an inclined leaky layer due to ditch recharge. Hydrol. Process. 20: 1597-1609, Doi: 10.1002/hyp.5947.

Jin, Y., Holzbecher, E. \& Sauter, M. 2014. A novel modeling approach using arbitrary Lagrangian-Eulerian (ALE) method for the flow simulation in unconfined aquifers. Computers \& Geosciences, 62: 88-94.

Karan, S., Engesgaard, P., Looms, MC., Laier, T. \& Kazmierczak, J. 2013. Groundwater flow and mixing in a wetland-stream system: Field study and numerical modeling. Journal of Hydrology 488: 73-83 .

Kim D.J. \& Ann M.J. 2001. Analytical solutions of water table variation in a horizontal unconfined aquifer: constant recharge and bounded by parallel streams. Hydrological Processes 15: 2691-2699.

Koussis, A.D., Smith, M.E., Akylas, E. \& Tombrous, M. 1998. Groundwater drainage flow in a soil layer resting on an inclined leaky bed. Water Resources Research 34(11): 2879-2887.

Liang, X. \& Zhang, Y.K. 2011. Analytical solution for drainage and recession from an unconfined aquifer. Groundwater 50(5): 793-798, Doi: 10.1111/j.1745-6584.2011.00867.x.

Marino, M.A. 1967. Hele-Shaw model study of the growth and decay of groundwater ridges. Journal of geophysical research 72(4): 1195-1205.

Marino, M.A. 1973. Water-table fluctuation in semipervious stream-unconfined aquifer systems. Journal of Hydrology 19: 43-52.

Olsen, J.S., Mortensen J. \& Telyakovskiy A.S. 2019. Polynomial approximate solutions of an unconfined Forchheimer groundwater flow equation. Advances in Water Resources 123:189-200.

Pauwels, V.R.N., Verhoest, N.E.C. \& Troch, F.P.D, 2002. A metahillslope model based on an analytical solution to a linearized Boussinesq equation for temporally variable recharge rates. Water Resour. Res. 38(12): 33-1-33-14, doi:10.1029/2001WR000714

Rotzoll, K., El-Kadi, A.I. \& Gingerich, S.B. 2008. Analysis of an unconfined aquifer subject to asynchronous dual-tide propagation. GroundWater 46: 239-250, doi:10.1111/j.1745-6584.2007.00412.x

Saadatnejadgharahassanlou, H., Ilkhanipour Zeynali, R., Vaheddoost B., \& Gharehbaghi A. 2020. Parametric and nonparametric regression models in study of the length of hydraulic jump after a multisegment sharp-crested V-notch weir. Water Supply 20(3): 809-818. https://doi.org/10.2166/ws.2019.198

Yeh, H.D., Huang, C.S., Chang, Y.C. \& Jeng, D.S. 2010. An analytical solution for tidal fluctuations in unconfined aquifers with a vertical beach. Water Resour. Res. 46(10): W10535, Doi:10.1029/2009WR008746

Zissis, T.S., Teloglou, I.S. \& Terzidis, G.A. 2001. Response of a sloping aquifer to constant replenishment and to stream varying water level. Journal of Hydrology 243: 180-191.. 